Journal of Accident and Emergency Medicine 1994 11, 238-242

\title{
A comparison of the backgrounds of first time and repeated overdose patients
}

\author{
C.J.TAYLOR, ${ }^{1}$ G.G.KENT ${ }^{2}$ \& R.W.HUWS ${ }^{3}$ \\ ${ }^{1}$ Accident and Emergency Department, Royal Hallamshire Hospital, Sheffield, ${ }^{2}$ Department of Psychiatry, \\ University of Sheffield and ${ }^{3}$ Middlewood Hospital, Sheffield
}

\section{SUMMARY}

This study examines the differences between two groups of parasuicide patients: 'first-timers' (patients admitted to hospital following their first overdose) and 'repeaters' (patients admitted with an overdose who had made at least one previous suicide attempt). The two patient groups were compared for factors known to increase the risk of parasuicide as well as for the experience of selfreported past sexual abuse and for symptoms of post traumatic stress disorder (PTSD). Out of a total of 100 patients interviewed, seven $(15 \%)$ of first-timers gave a history of sexual abuse and complained of an average of 0.55 symptoms of PTSD. Among repeaters, 28 (53\%) gave a history of sexual abuse and complained of an average of 1.84 symptoms of PTSD. Both results were statistically significant at $P<0.001$.

Key words: parasuicide, PTSD, sexual abuse

\section{INTRODUCTION}

Although many studies have been conducted on factors that increase the risk for parasuicide, few have examined differences between patients who have recently made their first attempt and those who have a history of parasuicide. Factors known to increase the risk of parasuicide include unemployment, ${ }^{1,2}$ a history of a previous attempt, ${ }^{3}$ substance abuse, ${ }^{4,5}$ disruption of family of origin, ${ }^{6,7}$ runaway behaviour, ${ }^{8}$ borderline and dissociative personality disorders ${ }^{9,10}$ and panic and somatization disorders. ${ }^{11,12}$ These latter four are probably part of a continuum of dissociative disorders, among which PTSD is perhaps the best known. PTSD can be understood as a pathologically persistent response to extreme emotional trauma (war, torture, rape, major catastrophes) and, in this society, sexual abuse is one of the most common causes. ${ }^{13}$
The aim of the present study is to test the hypothesis that repeaters would be more likely to have had certain types of experiences than those who present for the first time. In particular, the experience of sexual abuse was noted. Yeo \& $\mathrm{Yeo}^{14}$ reported that among a group of patients admitted following an overdose, those with a history of sexual abuse were significantly more likely to repeat the attempt within a 6-month follow-up period. Given that the above list of recognized risk factors for parasuicide shows a considerable overlap with the list of known sequelae of sexual abuse, we hypothesized that the two are associated with symptoms of PTSD. This study was designed to test the hypothesis that repetitive parasuicide behaviour is related to a history of sexual abuse and the presence of symptoms associated with PTSD.

\section{METHODS}

\section{Subjects}

All patients admitted to the Accident and Emergency (A\&E) Department at the Royal Hallamshire Hospital, Sheffied with the diagnosis of deliberate selfharm (DSH) - overdose were eligible to be entered into the study. As in the previous study by Yeo \& Yeo, ${ }^{14}$ patients who presented with other forms of DSH were excluded. First-timers, patients for whom the current episode was the first overdose, formed the comparison group. Repeaters, those who had taken at least one previous overdose, formed the study group. It was known that the proportion of first-timers to repeaters attending the host department was approximately $50 \%$, a figure that had been constant for several years. Given the reported level of $7.8 \%$ of patients having given a history of sexual abuse in the original study, we estimated that a sample size of 100 patients would confirm or refute the hypothesis. Of the 153 consecutive patients 
C.J. Taylor et al.

who fulfilled the inclusion criteria, 47 patients were either discharged or left hospital against medical advice before they could be seen, three refused consent and in a further three cases patients were acutely psychotic and could not give informed consent, leaving a final sample of 100 patients.

\section{Procedure}

Each morning during the 20-week study period, all patients admitted in the previous $24 \mathrm{~h}$ through the A\&E department with a diagnosis of 'DSH overdose' were identified from the A\&E register. Patients were visited on the ward and, after a brief explanation of the procedure and the aims of the study, they were asked for written consent. Patients were then given a questionnaire on demographic data and the 28-item General Health Questionnaire (GHQ). ${ }^{15}$ The latter is a widely-used screening measure of psychological distress which contains four sub-scales: somatic (e.g. 'Have you recently been feeling run down and out of sorts?'), anxiety (e.g. 'Have you recently lost much sleep over worry?'), social dysfunction (e.g. 'Have you recently felt incapable of making decisions about things?') and depression (e.g. 'Have you recently been thinking of yourself as a worthless person?'). The GHQ was scored according to the Likert method ( 0 , $1,2,3$ ) for the four responses which range from 'Not at all' to 'Much more than usual'.

During a 30-min semi-structured interview, patients were asked about their employment status, number of visits to their general practitioner (GP) in the previous 6 months, whether they had received psychiatric care sometime in their lives other than after a previous attempt, number of previous overdoses and/or other types of DSH, and substance abuse (over 21 units of alcohol per week, glue sniffing and use of hypnotics or street drugs). Patients were also asked about symptoms of somatization and panic disorder. Questions about previous experiences were divided into three areas: those relating to disruption of their childhood, physical abuse and sexual abuse. Childhood disruption was determined by whether they grew up with their parents or whether their they had been in care, fostered or orphaned before the age of 16 . A positive score for physical abuse was given if the patient had ever been hit with fists, beaten with belts, kicked while on the floor or threatened with a weapon. The prevalence of sexual abuse was determined by the answer to the question: 'Has anybody ever ticipate in a sexual act you did not want to perform at the time?' If the answer was in the affirmative to any of these three areas, patients were given the choice to relate details of the occurrence(s). Finally, patients were asked about the presence of several symptoms related to PTSD: ${ }^{16}$ nightmares, sleeplessness, avoidance reactions, intrusive thoughts or flashbacks relating to either abusive experiences or to other extreme events.

\section{Statistical analyses}

Data were analysed using an SPSSx package and required $t$-tests, Chi-Square tests and a regression analysis.

\section{RESULTS}

Tables 1 and 2 list the results for the total sample and for the comparison and study groups in ascending order of statistical significance. Table 1 gives the results for GHQ, Table 2 lists the frequencies of the factors surveyed.

\section{Total sample}

Although there were no selection criteria with regard to sex, the final total sample consisted of 50 male and 50 female patients, ranging in age from 16 to 69 years (mean $=30.4$ ). Of all patients, $70 \%$ reported one or more instances of physical abuse, and $35 \%$ reported sexual abuse. Males and females were equally likely to report physical abuse $\left(\chi^{2}=0.27\right.$, $\mathrm{df}=1, P>0.50$ ), but females were more likely to have been sexually abused $\left(\chi^{2}=7.98\right.$, $\mathrm{df}=1$, $P<0.01$ ).

Table 1. Mean scores on General Health Questionnaire for the total sample and for first-timers and repeated overdose patients. Degrees of freedom (df) vary because of missing data

\begin{tabular}{lrrrrrrr}
\hline GHQ & $\begin{array}{c}\text { Total } \\
\text { sample }\end{array}$ & $\begin{array}{c}\text { First- } \\
\text { timers }\end{array}$ & Repeaters & $t$ & df & $P<$ \\
\hline Somatic & 3.38 & 2.82 & 3.84 & 2.27 & 93 & 0.05 \\
Anxiety & 4.64 & 4.29 & 4.95 & 1.51 & 92 & n.s. \\
Social & & & & & & \\
dysfunction & 3.56 & 2.70 & 4.33 & 3.29 & 92 & 0.001 \\
Depression & 5.07 & 4.41 & 5.67 & 2.84 & 92 & 0.01 \\
Total & 16.64 & 14.22 & 18.77 & 2.85 & 91 & 0.01 \\
\hline
\end{tabular}




\begin{tabular}{|c|c|c|c|c|c|c|c|}
\hline \multirow[t]{18}{*}{$\begin{array}{l}\text { A comparison of } \\
\text { parasuicide } \\
\text { patients }\end{array}$} & sample & Total & $\begin{array}{l}\text { First- } \\
\text { timers }\end{array}$ & Repeaters & $\begin{array}{c}\text { Results of } \\
\chi^{2} \text { or } t\end{array}$ & $\mathrm{df}$ & $P<$ \\
\hline & Somatic & & & & & & \\
\hline & symptoms & 43 & $16(34 \%)$ & $27(51 \%)$ & $2.82\left(\chi^{2}\right)$ & 1 & n.s. \\
\hline & Unemployed & 38 & $15(32 \%)$ & $23(43 \%)$ & $1.39\left(\chi^{2}\right)$ & 1 & n.s. \\
\hline & Disrupted & 52 & $20(43 \%)$ & $32(60 \%)$ & $0.17\left(\gamma^{2}\right)$ & 1 & $n s$ \\
\hline & Physical & & & & & & \\
\hline & abuse & 70 & $30(64 \%)$ & $40(75 \%)$ & $1.46\left(\chi^{2}\right)$ & 1 & n.s. \\
\hline & $\begin{array}{l}\text { Average no. } \\
\text { of substances }\end{array}$ & & & & & & \\
\hline & abused & 0.68 & 0.58 & 0.74 & $0.58(t)$ & 93 & n.s. \\
\hline & Panic & & & & & & \\
\hline & symptoms & 32 & $10(21 \%)$ & $22(42 \%)$ & $4.37\left(\chi^{2}\right)$ & 1 & 0.05 \\
\hline & Past psychiatric & & & & & & \\
\hline & history & 36 & $11(23 \%)$ & $35(66 \%)$ & $17.41\left(\chi^{2}\right)$ & 1 & 0.001 \\
\hline & $\begin{array}{l}\text { Past DSH } \\
\text { (other than }\end{array}$ & & & & & & \\
\hline & overdose) & 17 & $0(0 \%)$ & $17(31 \%)$ & $15.99\left(\chi^{2}\right)$ & 1 & 0.001 \\
\hline & $\begin{array}{c}\text { Average no. } \\
\text { of PTSD }\end{array}$ & & & & & & \\
\hline & symptoms & 1.25 & 0.55 & 1.84 & $4.28(t)$ & 95 & 0.001 \\
\hline & $\begin{array}{l}\text { History of } \\
\text { sexual abuse }\end{array}$ & 35 & $7(15 \%)$ & $28(53 \%)$ & $13.99\left(\chi^{2}\right)$ & 1 & 0.001 \\
\hline
\end{tabular}

Table 2. Numbers (percentages) of patients for total sample, first-time and repeat/overdose patients for ten factors surveyed. Degrees of Freedom (df) vary because of missing data

\section{Comparisons between first-time and repeated overdose patients}

Forty-seven patients reported that the index episode was their first overdose; 53 patients were repeaters, reporting an average of 4.75 previous overdoses. There was no significant difference in age between the two groups (means $=28.6$ and 32.0 years respectively, $t(98)=0.17, P>0.10)$.

Tables 1 and 2 indicate that repeaters scored significantly higher on the somatic, social dysfunction and depression scales on the GHQ and on five out of the ten factors surveyed: panic disorder, other forms of DSH (excluding overdoses), past history of psychiatric care, sexual abuse and number of PTSD symptoms.

In order to establish the relative importance of these factors, they were regressed on the number of previous attempts. Age, gender, number of GP visits, previous psychiatric contact and the experience of physical violence were also included. Three variables were entered into the regression equation: as shown in Table 3, the reports of symptoms of PTSD, other forms of DSH, and sexual violence together accounted for $52 \%$ of the variance in overdose attempts. Although as noted earlier patients who had been sexually abused were
Table 3. Results of multiple regression analysis on number of previous overdose attempts for total sample

\begin{tabular}{lcccc}
\hline & Multiple $R$ & $R^{2}$ & $F$ & $P<$ \\
\hline PTSD Symptoms & 0.622 & 0.387 & 53.72 & 0.001 \\
DSH & 0.698 & 0.487 & 39.89 & 0.001 \\
Sexual abuse & 0.720 & 0.519 & 29.80 & 0.001 \\
\hline
\end{tabular}

predominately female, gender was not entered into the equation.

Characteristics of sexual abuse in repeated overdose attempts

To determine what patients had perceived as 'having been forced to participate in a sexual act...', the descriptions of the 28 survivors (22 female, six male) in the repeaters group were analysed. For 23 $(82 \%)$ patients the abuse involved forced vaginal, anal or oral intercourse; in $18(64 \%)$ patients, the abuse had occurred before the age of 16 and for 17 $(61 \%)$ patients the abuse had been prolonged over months and sometimes years. 
DISCUSSION

The results of this study support previous research. Patients who had made at least one previous attempt were more likely to have engaged in other forms of DSH, to score more highly on the GHQ, to have experienced symptoms of panic attacks and to have suffered sexual abuse. On the regression analysis, the number of previous overdoses was best predicted by reports of nightmares, flashbacks and other symptoms of PTSD.

However, these conclusions must be tempered by some criticisms that can be made of this study. Perhaps the most important is the problem of dating the onset of the symptoms. It is possible that the DSH and symptoms of PTSD occurred after the parasuicidal behaviour had become established, or may even have been a consequence of it. There may have been other, unrelated, life events which could have accounted for the differences between first-timers and repeaters. This could have been clarified further if a third group of A\&E attenders (e.g. accident victims) had also been interviewed in order to ascertain their frequency of reported abuse and PTSD symptoms. In addition, no formal assessment of PTSD was undertaken and it is unclear what proportion of patients would meet the diagnostic criteria for PTSD. Although the interviewer was given training in the elicitation of PTSD symptoms, she was not a psychiatrist or clinical psychologist.

While these methodological problems present difficulties for the interpretation of the data, it should be noted that the classification of first-time versus repeated overdose patients used in this study provides a conservative test of differences between groups. This is the case for two reasons: first, statistically at least, approximately a quarter to a third of the first-time group will go on to make another suicide attempt; second, it is possible that some of the first-time group did not disclose previous attempts.

Despite these criticisms, the results suggest a link between repeated overdosing, sexual abuse and symptoms of PTSD. While the results are suggestive, it cannot be concluded that abuse leads to PTSD which leads to DSH in any linear sequence. The main conclusion of these results is support for the findings of $\mathrm{Yeo} \& \mathrm{Yeo}^{14}$ that repeat overdose patients are more likely to have a history of sexual abuse than first time patients. The nature of any association between abuse and overdosing requires the collection of further details of precipitating events. The addition of questionnaires, such as the Impact of Event Scale, ${ }^{17}$ which are designed to provide a more objective measure of symptoms of PTSD, would be helpful.

If a link between abuse, PTSD and repeated overdosing were to be confirmed, those patients who had experienced abuse would benefit from systematic assessments in these areas. By instituting interventions which are designed to assist patients who had been abused, ${ }^{10}$ the likelihood of further attempts might be reduced. Second, the confirmation of such a link might make it easier for A\&E staff to appreciate the difficulties faced by repeat overdose patients. It seems that many medical staff have negative views towards parasuicide patients. ${ }^{18}$ Perhaps they would be more sympathetic and the need for adequate follow-up would be taken seriously if the reasons for the distress were apparent.

\section{ACKNOWLEDGEMENTS}

The authors wish to thank the Consultant Physicians who allowed us to interview their patients.

\section{REFERENCES}

1. Platt S. \& Dyer J. (1987) Psychological correlates of unemployment among male parasuicides in Edinburgh. British Journal of Psychiatry 151, 27-32.

2. Standish-Barry H., Clayden A. \& Sims A. (1989) Age, unemployment and parasuicide in Leeds. International Journal Social Psychiatry 35, 303-312.

3. Robinson A. \& Duffy J. (1989) A comparison of selfinjury and self-poisoning from the Regional Poisoning Treatment Centre, Edinburgh. Acta Psychiatrica Scandinavica 80, 272-279.

4. Michel K. (1987) Suicide risk factors: A comparison of suicide attempters with suicide completers. British Journal of Psychiatry 150, 78-82.

5. Gomberg E. (1989) Suicide risk among women with alcohol problems. American Journal of Public Health 79, 1363-1365.

6. Silove D., George G. \& Bhavani-Sankaram V. (1987) Parasuicide: interaction between inadequate parenting and recent interpersonal stress. Australian and New Zealand Journal of Psychiatry 21, 221-228.

7. Wasserman D. \& Cullberg J. (1989) Early separation and suicidal behaviour in the parental homes of $\mathbf{4 0}$ consecutive suicide attempters. Acta Psychiatrica Scandinavica 79, 196-202.

8. Stiffman A. (1989) Suicide attempts in runaway youths. Suicide and Life-threatening Behaviour 19, 147-159.

9. Edwall G., Hoffman N. \& Harrison P. (1989) Psy- 
A comparison of parasuicide patients chological correlates of sexual abuse in adolescent girls in chemical dependency treatment. Adolescence 24, 279-288.

10. Cahill C., Llewelyn S. \& Pearson C. (1991) Long-term effects of sexual abuse which occurred in childhood: A review. British Journal of Clinical Psychology 30, 117-130.

11. Weissman M., Klerman G., Markowitz J. et al. (1989) Suicidal ideation and suicide attempts in panic disorder and attacks. New England Journal of Medicine 320, 1209-1214.

12. Noyes R. (1991) Suicide and panic disorder: A review. Journal of Affective Disorders 22, 1-11.

13. Braun B.G. (1989) Psychotherapy of the survivor of incest with a dissociative disorder. Psychiatric Clinics of North America 12(2), 307-323.
14. Yeo H.M. \& Yeo W. (1993) Repeat deliberate selfharm: a link with childhood sexual abuse? Archives of Emergency Medicine 10, 161-166.

15. Goldberg D. \& Hillier V. (1979) A scaled version of the General Health Questionnaire. Psychological Medicine 9, 139-145.

16. American Psychiatric Association (1980) Diagnostic and Statistical Manual of Mental Disorders, 3rd edn, revised. American Psychiatric Association, Washington.

17. Horowitz M., Wilner N. \& Alvarez W. (1979) Impact of event scale: a measure of subjective stress. Psychosomatic Medicine 41, 209-218.

18. Goldney R. \& Bottrill A. (1980) Attitudes towards patients who attempt suicide. Medical Journal of Australia 2, 717-720. 